\title{
Attenuation of schedule-induced polydipsia by trihexyphenidyl'
}

\section{J. D. KEEHN and MARTHA NAGAI, York University and Addiction Research Foun- dation, Toronto, Ontario, Canada}

Trihexyphenidyl in the dosage $1.5 \mathrm{mg} / \mathrm{kg}$ did not affect the normal growth and water consumption of six white rats in comparison with six Ss injected with saline. Of eight other rats reinforced with food on a VI 60-sec schedule, six developed polydipsia. All six Ss consumed less water following trihexyphenidyl injections than they did in control sessions. Only two $S$ s recovered baseline water intakes following drug withdrawal.

Cholinergic drugs like acetylcholine and carbachol elicit drinking by satiated animals when small quantities are placed directly into certain regions of the brain (Fisher \& Coury, 1962; Grossman, 1960). Prior injection of anticholinergic drugs like atropine and scopolamine block this effect (Grossman, 1962; Levitt \& Fisher, 1966; Stein, 1963). We wondered if excessive drinking induced by a behavioral technique would similarly be blocked by an anticholinergic drug. We used the Falk (1961) procedure to create excessive water in take, and examined the efficacy of the anticholinergic agent trihexyphenidyl (Artane) in controlling this intake. We selected trihexyphenidyl as the anticholinergic agent because, unlike atropine, it causes only a mild dryness of the throat (Doshay, Constable, \& Zier, 1954). The Artane was supplied by Lederle Laboratories in powder form.

\section{SUBJECTS}

Twenty naive male Wistar albino rats between 100 and 120 days of age were used. They were housed in individual home cages and, except for $\mathrm{S} 5$, always provided with unlimited water. Twelve Ss also had unlimited food.

\section{APPARATUS}

Two Grason-Stadler Model E 3125 B two-bar rat boxes were used. In each the left bar was removed and its opening covered with a metal plate flush with the wall. A Richter tube filled with water protruded into each chamber $3.75 \mathrm{~cm}$ above floor level and $10 \mathrm{~cm}$ from the wall containing the bar and pellet receptacle. Electronic programming and recording equipment was activated by a force of $22 \mathrm{~g}$ on the bar. The chambers were enclosed in ventilated chests.

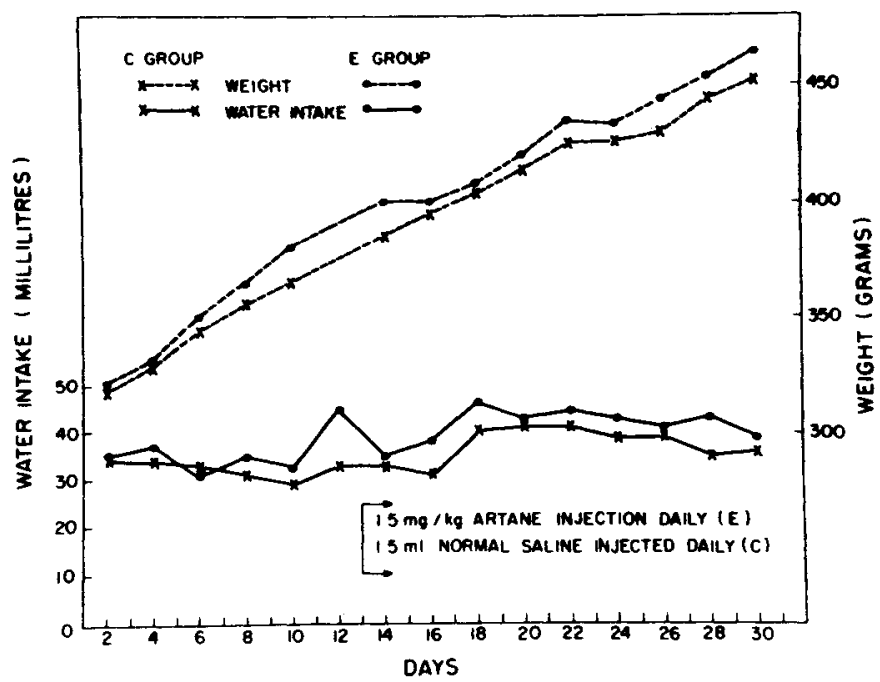

Fig. 1. Median daily weight and water intake curves of six rats treated with Artane (E group) and six rats treated with saline (C group).

\section{PROCEDURE}

Twelve Ss were given free water and standard Rockland rat diet for 31 days in their home cages. Their weights and water intakes were recorded daily. From the 12 th day onward they were injected (ip) with either $1.5-\mathrm{ml}$ isotonic saline (Group C, six Ss) or $1.5-\mathrm{mg} / \mathrm{kg}$ Artane (Group E, six Ss) immediately after they were weighed and their water intakes recorded.

Eight Ss were adapted to a feeding rhythm which maintained them at about $80 \%$ of their estimated free-feeding weights. They were trained to bar press for 45-mg Noyes rat pellets with adjusting schedules which stabilized at VI $60 \mathrm{sec}$ for

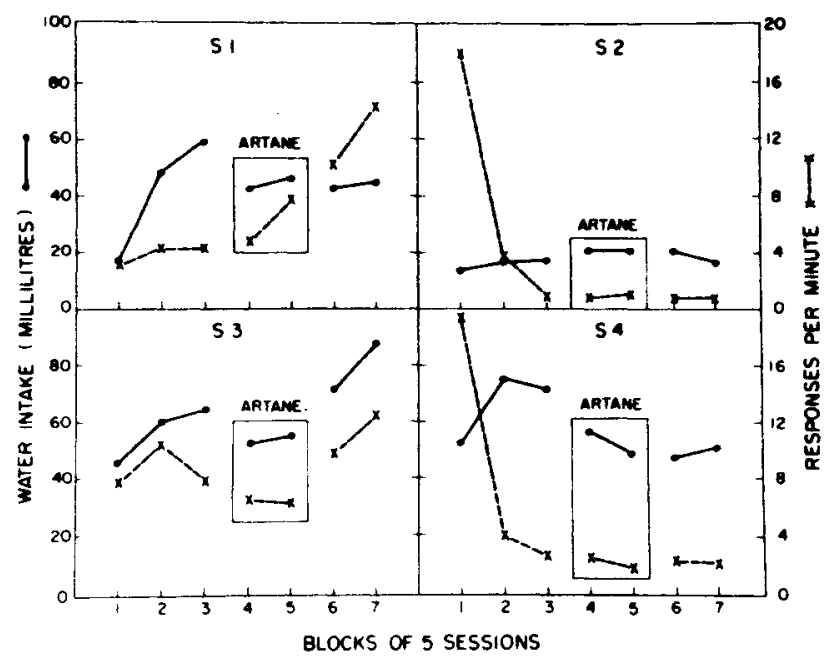

Fig. 2. Water intake and response rates of each of four rats reinforced with food on a variable-interval 1-min schedule under no-drug and trihexyphenidyl-injected conditions. For Rat S3 the left-hand scale applies to both intake and response rate measures. 


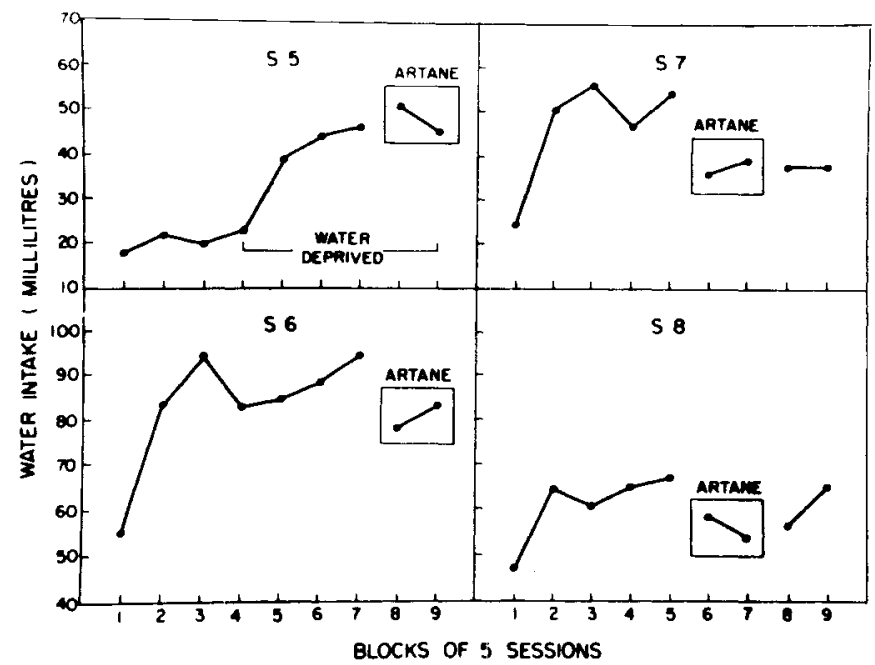

Fig. 3. Water intake of each of four rats reinforced with food on a variable-interval 1-min schedule under no-drug, salineinjected, and trihexyphenidyl-injected conditions. Due to apparatus failure Block 4 points are based on only three sessions. Animal S5 was water as well as food deprived from Block 4 onwards.

3-h sessions. Animals S1 through S4 were run for 35 consecutive daily sessions on this schedule. On Sessions 16 through 25 these Ss were injected (ip) with $1.5 \cdot \mathrm{mg} / \mathrm{kg}$ Artane just before a session began. Animals S5 through S8 were run for 45 consecutive daily sessions. These Ss were injected (ip) with $1.0 \mathrm{ml}$ isotonic saline 20 to $30 \mathrm{~min}$ before Sessions 24 and 25 . This injection was continued for S5 and S6 on Sessions 26 through 35 while $\mathrm{S} 7$ and S8 were injected with $1.5 \cdot \mathrm{mg} / \mathrm{kg}$ Artane. The injected solutions were switched on Sessions 36 through 45 . The $E$ recording data did not know which injection an $S$ received. Supplementary feedings of Rockland diet to maintain body weight were given to all Ss $30 \mathrm{~min}$ after each session.

\section{RESULTS}

Median daily weights and water intakes for the $\mathrm{E}$ and $\mathrm{C}$ groups are shown in Fig. 1 . There was little difference between the groups. All Ss exhibited normal weight changes from about $315 \mathrm{~g}$ to about $460 \mathrm{~g}$ and they all consumed water in the normal range of 30 to $40 \mathrm{ml}$ per day.
The amount of water consumed and the number of bar presses emitted per session, averaged over blocks of five sessions, are shown for Ss 1 through 4 in Fig. 2. Despite the great variability in bar-press rates across animals (the bar-pressing rate of $\mathrm{S} 3$ is indicated by the left-hand, not the right-hand, scale of Fig. 2) and across sessions, all Ss obtained close to the theoretically maximum number of reinforcements (180) in every session. Three of the Ss exhibited polydipsia, and all three Ss consumed less water following Artane injections. However, only one S (S3) resumed heavy drinking when the drug was withdrawn.

Water consumption data for Ss 5 through 8 are shown in Fig. 3. Animal S5 did not become polydipsic until it was deprived of water in its home cage following Session 20. Artane did not reduce this animal's water intake; it did reduce that of the other three Ss. But, once again, only one of these Ss (S8) recovered its predrug water consumption when the drug was withdrawn. During all drug and predrug sessions response rates of $\mathrm{S} 5, \mathrm{S6}$,
$\mathrm{S} 7$, and $\mathrm{S} 8$ averaged around $11,33,5$, and 11 bar presses per minute, respectivcly postdrug rates remained the same excep 1 that S8's rate rose to about 20 presses per minute when Artane was withdrawn. All Ss obtained close to the maximum number of reinforcements on every session.

\section{DISCUSSION}

The finding that anticholinergic drugs can reduce chemically elicited excessive drinking by rats was confirmed when excess drinking was generated by a behavioral technique. Artane, in the dosage we employed, attenuated the water consumption of rats made polydipsic but it did not affect the amount of water consumed by nonpolydipsic animals (Levitt \& Fisher, 1967). Nor did it affect the number of food reinforcements consumed by any of the animals.

\section{REFERENCES}

DOSHAY, L. J., CONSTABLE, K., \& ZIER, A. Five-year follow up of treatment with trihexyphenidyl (Artane). Journal of the American Medical Association, 1954, 154, 1334-1336.

FALK, J. L. Production of polydipsia in normal rats by an intermittent food schedule. Science, $1961,133,195-196$

FISHER, A. E., \& COURY, J. N. Cholinergic tracing of central neural circuit underlying the thirst drive. Science, 1962, 138, 691693.

GROSSMAN, S. P. Eating and drinking elicited by direct adrenergic or cholinergic stimulation of hypothalamus. Scienc, 1960, 132, 301-302.

GROSSMAN, S. P. Effects of adrenergic and cholinergic blocking agents of hypothalamic mechanisms. American Journal of Physiology. $1962,202,1230-1236$.

LEVITT, R. A., \& FISHER, A. E. Anticholinergic blockade of centrally induced thirst. Science, 1966, 154, 520-522.

LEVITT, R. A., \& FISHER, A. E. Failure of central anticholinergic brain stimulation to block natural drinking. Phy siology \& Behavior, $1967,2,425-428$

STEIN, L. Anticholinergic drugs and the central control of thirst. Science, $1963,139,46-48$.

$$
\text { NOTE }
$$

1. Selection of trihexyphenidyl was made after consultation with Dr. Joan Marshman of the Addiction Research Foundation, whose assistance is gratefully acknowledged. We are also grateful for the assistance of Mr. L. Grupp and Mr. M. Di Franco of the University of Toron to in running the experiments. 